\title{
Slotted shell resilient elements for drilling shock absorbers
}

\author{
Andrii Velichkovich ${ }^{1}$, Taras Dalyak $^{2}$, and Ivan Petryk ${ }^{1, *}$ \\ ${ }^{1}$ Department of Applied Mechanics, Ivano-Frankivsk National Technical University of Oil and Gas, 15 Karpatska St., \\ 76019 Ivano-Frankivsk, Ukraine \\ ${ }^{2}$ Ivano-Frankivsk Branch of Pidstryhach Institute for Applied Problems of Mechanics and Mathematics National \\ Academy of Sciences of Ukraine, 3 Mykytynetska Str., 76002 Ivano-Frankivsk, Ukraine
}

Received: 22 February 2018 / Accepted: 19 July 2018

\begin{abstract}
The new design of a resilient element for application in drilling devices of vibration protection is presented. A cylindrical shell with a cut along its generatrix is the peculiarity of the proposed design. The presented resilient element has high loaded and damping properties upon cross dimension hard restriction condition. Besides, the design is simple, technological and low cost. The drilling shock absorber is tested, which is manufactured on the base of several slotted shell resilient elements, operating in parallel manner. A calculation method for slotted shell resilient elements for drilling devices vibration protection is given. This work presents results of slotted cylindrical shell study in conditions of contact interaction with a resilient filler. To provide the research, the authors have developed a verified numerical model of the shell resilient element with a slit and used iterative algorithms for contact problem solving, considering contact surface friction. The stress-strain state of the shell resilient element of the drilling shock absorber was analyzed. Strength of the structure is evaluated by the energy criterion. Hysteresis loops were developed and analyzed for some histories of resilient element cyclic loading. The obtained results make possible rather accurately to take into account effect of the shell and the filler material resilient characteristics, their geometrical parameters and tribological properties on operational characteristics of drilling devices for vibration protection. In its turn, this makes possible to use efficient drilling vibration protection devices, develop vibroinsulator shell designs by the criteria of maximum compliance and required damping level.
\end{abstract}

\section{Introduction}

The process of drilling oil and gas wells is associated with appearance large vibration of a drilling tool. The presence of these vibrations reduces technical and economic parameters of the drilling, adversely affect on operation of elements of the drill string, bits, downhole motors and the surface equipment, and also worsens the working conditions of drilling crews $[1-5]$. When drilling with intense vibration conditions, the endurance of cone bits and diamond crowns reduces, the useful power of downhole motors is lost, the specific energy consumption increases, the percentage of core removal decreases, and the accidence increases. During drilling at shallow depth, it is possible usually visually to observe vibration of the driving pipe. With increasing depth of the well, the drill string can collapse without visible manifestations of vibrations on the surface. Vibration load during drilling of hard rocks has a significant effect on distortion of the borehole [5-7]. Consequently, the problem of

\footnotetext{
* Corresponding author: iyap@ukr.net
}

reduction harmful effects of vibration in drilling has special significance, and research ways solutions are very urgent task.

At present, a number of technical measures, methods and devices are proposed, the purpose of which is to reduce the harmful effects of vibrations and to regulate the dynamic mode of the drill string. To positive results, namely, a decrease in the intensity of twisting oscillations, leads to the provision of high quality (especially lubricating properties) of the drilling mud [8]. One promising way reduce drill string self-excited oscillation should be considered the development of bit designs with a minimum slope of the curve of the torque characteristics and provide high quality cleaning bottom hole [9]. The positive results are obtained by the choice of antivibration layouts of the tool, application of light alloy, in particular aluminum pipes with relatively low modulus of elasticity, etc. [3, 4, 10].

One of the most promising and radical solutions to the problem based on application of special vibroprotection devices: resilient couplings, dampers and drilling shock absorbers, resilient spindle of downhole motors, dynamic suppressors, etc. [11, 12]. Note that now a lot of famous 
in the world manufacturers and suppliers of drilling equipment offer their customers drilling shock absorbers [13-16]. It is noteworthy that the operating principle of the proposed vibroprotection equipment for the drill string from different manufacturers is fundamentally different.

In particular, the company "Toro Downhole Tools" (USA) manufactures hydraulic drilling shock absorbers "Shock Subs SH", and "JA Oilfield Manufacturing, Inc." offers "Shock Sub System" based on Belleville springs $[13,16]$. The famous Swiss manufacturer "Weatherford International Ltd." advertises rubber-metal shock absorbers of model "Dailey R-A-M". Recognized as the world leader in the manufacture and service downhole motors company "BICO Drilling Tools" produces shock absorbers "ShockEZE" based on oil-filled Belleville springs of original design. Leading Chinese companies "Secoroc Rock Drilling Tools" and "Jereh Drilltech" offer drilling vibration dampers single- and two-way acting based on oil or rubber resilient elements [15]. Russian manufacturer "INTEGRA VNIIBTDrilling Tools Ltd." makes shock absorbers based on metallic resilient elements [16].

This diversity of technical solutions demonstrates that the use of traditional resilient elements in drilling vibration protection devices does not always provide a sufficient level of their efficiency in difficult operating conditions of a well (high static and dynamic load while limiting a transverse size). Obviously, the task of optimal choice and rational design of the resilient element for drilling tools vibration protection remains without final solution.

Formulate the purpose of the article. In the present research, authors set themselves two main tasks:

1. Develop reliable and efficient design of the resilient element for the drilling shock absorber that is able working in difficult conditions at drilling of wells;

2. Offer an evaluation methodology for basic operational characteristics (hardness, strength and damping properties) of this resilient element.

\section{Slotted shell resilient elements}

Basic requirements for modern vibro-protection system include: minimal size and weight, stability vibro-protection properties, technological manufacture, reliability of operation and low cost. Besides, the design of resilient elements for drilling shock absorbers, that are subject to extreme loads, is necessary to combine high load capacity of the device with relatively low stiffness and necessary level damping, sufficient for efficient damping.

In order to solve the tasks discussed, the authors' team proposed the idea of using a cylindrical shell with a slit along the generatrix as the main loaded and executive link of the resilient element. This performance structurally anisotropic loaded link (stiff in the axial direction and compliant in the tangential) is created the opportunity to use bend of the shell in conditions close to the plane deformation. It is allowed in the design stage of the device to vary stiffness and damping properties of the resilient element in a wide range.

In Figure 1 are shown a general view and a schematic diagram of the slotted shell resilient element $[17,18]$. The peculiarity of the presented model is the slot of the loaded shell along its generatrix. Such performance shells are allowed to reduce the stiffness of shell resilient elements without losses their damping properties. The principle of operation of the device (Fig. 1b) based on the resilient element is following. Applied to the pistons 3 axial load causes them to move into the slotted shell 1 , thus compressing a resilient filler 2. The resilient filler 2, changing own shape, begins contact interaction with the slotted shell 1 . Consequently, the shell, is being deformed, accumulates the potential energy of the resilient deformation. The main contribution to compliant of the system makes changing of shape of the filler due to bending of the slotted shell. At the disappearance (or decrease) of the external load, moving parts of the system return to the initial (or intermediate) position through the accumulated energy. Part of the energy, supplied to the system from external influences, dissipated mainly by the relative slipping with friction of the filler and the shell. Therefore, at the same time the resilient element has amortization and damping properties.

For qualitative implementation described principle of operation and achievement of the required operational characteristics of the vibroinsulator, its components must have certain properties. The main energy storage (slit shell 1) requires a combination of low stiffness with the necessary level of strength and durability. For directed transformation of displacements, the filler 2 should easily change own shape (i.e., it has a low shear modulus). From this point of view, the filler material is soft compared with the shell material. On the other hand, to make the shell is deformed under contact interaction of the filler material should be low compressible (i.e., it has a high volume compression module). Tribological properties of shell-filler pair are selected for reasons of ensuring, in specific operation case, the necessary level of damping (hysteresis of energy dissipation at dry friction).

\section{Drilling shock absorber based on slotted shell resilient elements}

Usually, shock absorbers for vibrations of the drill string are set between the bit and heavy-weight drill pipe or between the bit and the downhole motor, that does not exclude possibility their installation elsewhere of the drill string, for example, for technological or local protective tasks.

Figure 2 presents a general view and a principal scheme of the original model of drilling shock absorber, which is equipped stepped the resilient element. The main loaded part of the resilient element of this shock absorber is the cylindrical shell with a cut along the generatrix. The feature of the presented model is the parallel operation of resilient elements of the shock absorber. The shock absorber has adapter 1 , the body 2 , the support bushing 3 , the resilient element of the first stage 4 , the shaft 5 , the resilient element of the second stage 6 , the activation bushing for the resilient 


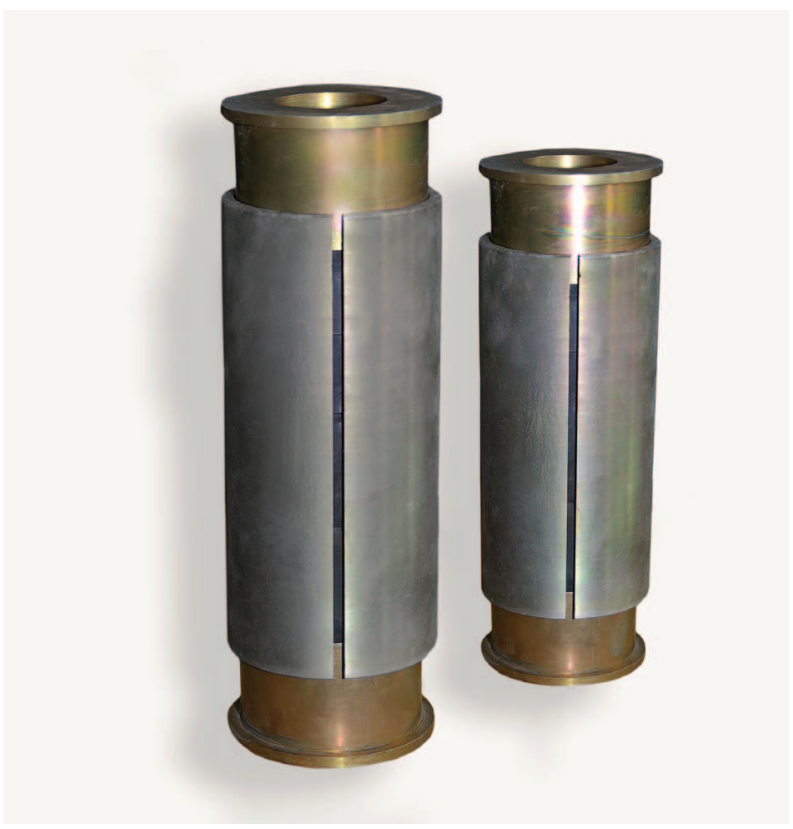

a)

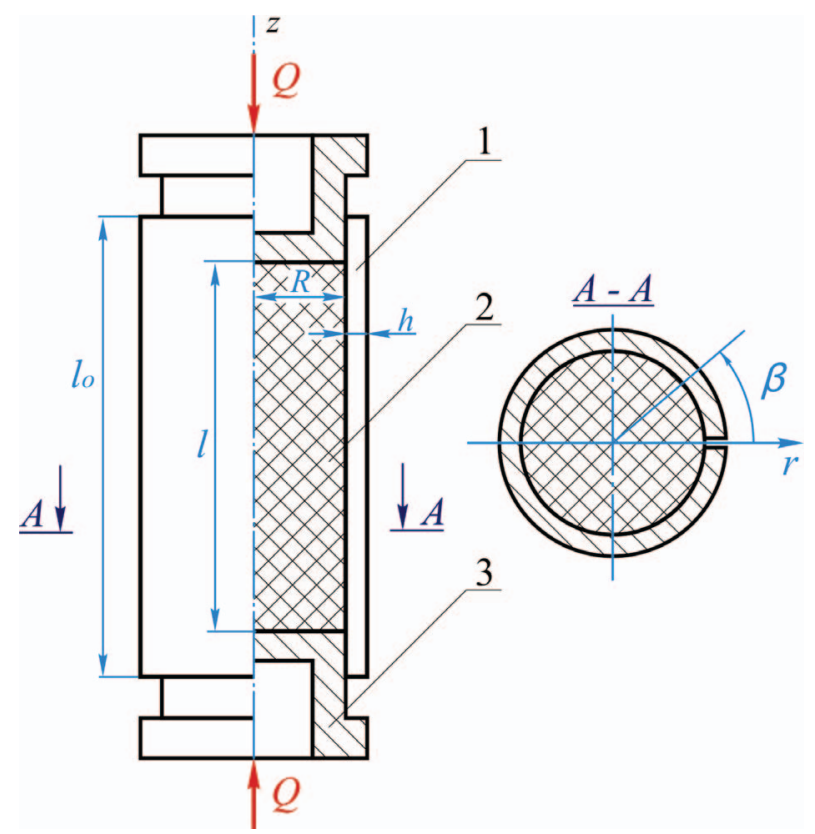

b)

Fig. 1. Slotted shell resilient element: (a) the view of resilient elements; (b) design of the resilient element.

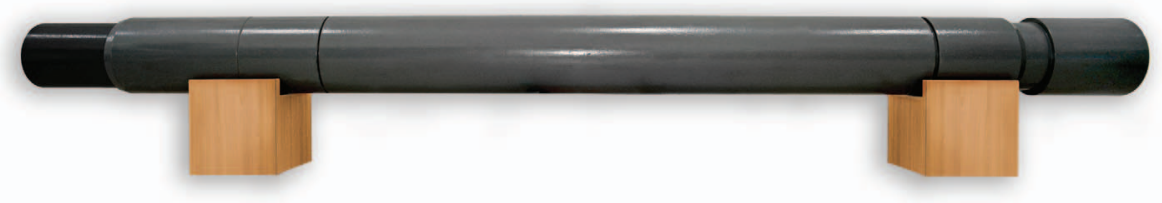

a)

b)

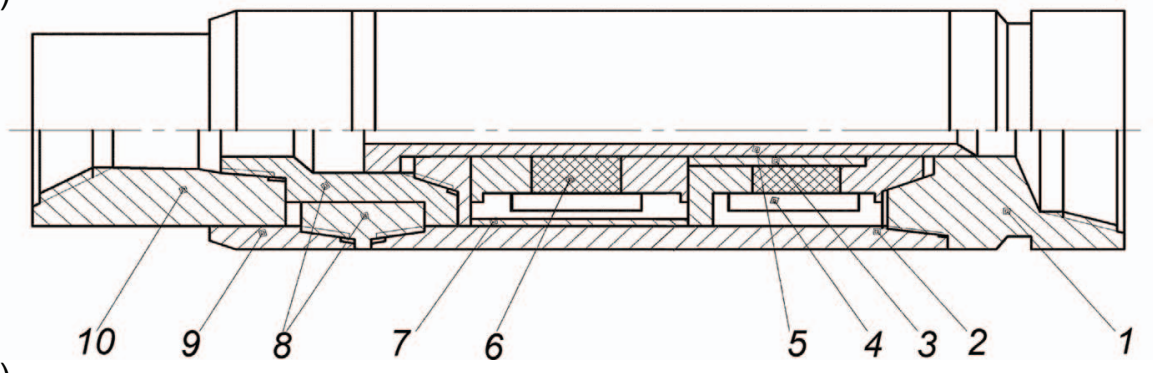

Fig. 2. The drill shock absorber is designed on the slotted shell resilient elements: (a) the general view of the industrial one; (b) the design of the shell shock absorber.

element of the first stage 7 , a profile (square) pair transmission torque 8 , centralizer 9 , adapter for a bit 10 . The shock absorber works as follows. Under the action of the external axial load, the shock absorber movable parts come into the body 2 . At the same time the stepped resilient element, what consists from the shell resilient elements 4 and 6 , accumulates the elastic deformation energy. When the external load reduces, the resilient element due to the accumulated energy returns movable parts of the shock absorber to initial position. Due to presence bushings 3 and 7 stages of resilient elements are activated in parallel operation, thus each of them loaded the part of an external force, which is proportional to its own stiffness.

In other words, the slotted shell resilient elements 4 and 6 are installed on the shaft 5 sequentially, but due to the interaction with bushings 3 and 7 operate parallel. This is the same way, if we installed stages 4 and 6 between two rigid plates and loaded such force $Q$, which will operate in 


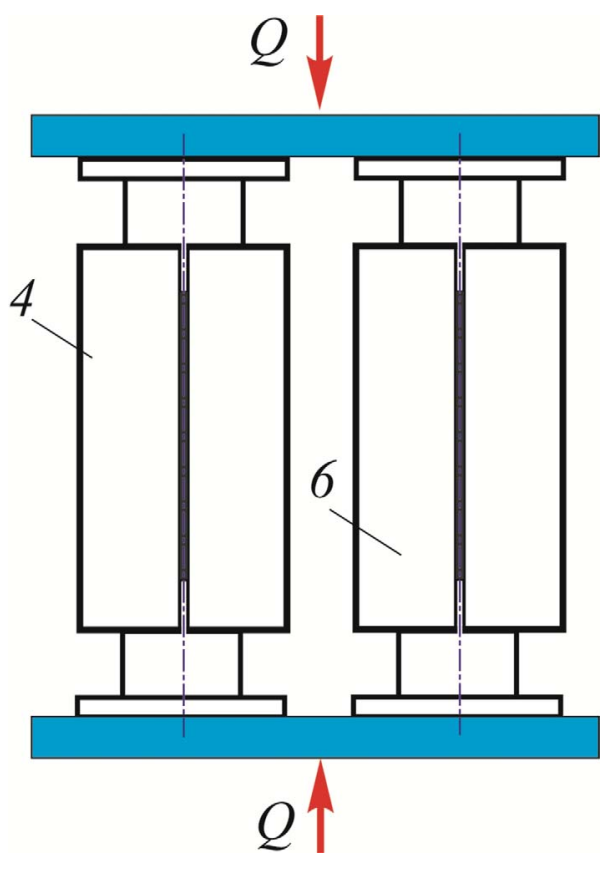

Fig. 3. The scheme of interaction of shell resilient elements in the drilling shock absorber.

the drilling shock absorber (Fig. 3). It should be noted that if necessary it is possible to install more number of stages that will at once or sequentially (with increasing of the external load) activate to parallel work.

In cyclic loading of the drilling shock absorber of this type, as result frictional interaction fillers and shells of resilient elements, the part of energy, supplied to the system, is dissipated, due to effect of construction hysteresis.

Analysis of results of industrial tests for presented shock absorber design with rotary drilling half-hard rocks showed increasing penetration bits at $27 \%$ and increase deepening speed at $15 \%$ [19].

\section{Mathematical modeling of slotted shell resilient element}

Successful design and using of drilling shock absorbers essentially depend from the quality of theoretical and experimental researches of loaded parts. The main concepts of mechanical and mathematical modeling, calculation and experimental researches of shell resilient elements and other layered structures that are based on continuous shells published in the works [20-24]. Theoretical researches slotted shell resilient elements are missing in the literature now.

In terms of mechanics, the proposed resilient element is the deformable shell system with dry friction. At mechanics and mathematical modeling of behavior for this shell resilient element in conditions of nonmonotonic loading, it is obtained structurally nonlinear nonconservative mixed contact problem of friction interaction of the thin slotted shell with the resilient filler. For solving this problem, we decided to use the numerical method of finite elements. In the previous research, authors of this article constructed verified finite-element model of contact interaction of the slotted shell and the resilient body. The verification was performed by comparing a series of results, obtained by numerical way, with results of experimental researches of specimens [25].

It was considered the problem of friction interaction of the resilient filler $(r, \beta, z) \in[0, R] \times[0,2 \pi] \times[0, l / 2]$ with the resilient shell $(r, \beta, z) \in[R, R+h] \times[0,2 \pi] \times\left[0, l_{\mathrm{o}} / 2\right]$ for compression the filler by smooth absolutely rigid pistons with the force $Q$ (Fig. 1b).

The three-dimensional contact problem of elasticity theory is solved for these boundary conditions.

On the surface of contact $r=R, \beta \in[0,2 \pi),|z| \in[0, l / 2]$

$$
\left\{\begin{array} { l } 
{ \sigma _ { r } \leq 0 , [ u _ { r } ] = 0 ; } \\
{ \sigma _ { r } = 0 , [ u _ { r } ] \geq 0 , }
\end{array} \left\{\begin{array}{l}
\vec{\tau}_{r}=f \sigma_{r}\left[\frac{[\vec{v}]}{[\vec{v}] \mid},[\vec{v}] \neq 0\right. \\
\left|\vec{\tau}_{r}\right| \leq-f \sigma_{r},[\vec{v}]=0
\end{array}\right.\right.
$$

At ends of the filler:

$$
\begin{aligned}
& \text { for } r \in[0, R], \beta \in[0,2 \pi], z=1 / 2 \\
& \qquad \int_{0}^{2 \pi} \int_{0}^{R} \sigma_{z} r \mathrm{~d} r \mathrm{~d} \beta=-Q, \vec{\tau}_{z}=0, u_{z}=-\delta ;
\end{aligned}
$$

$$
\begin{aligned}
& \text { for } r \in[0, R], \beta \in[0,2 \pi], z=0 \\
& \vec{\tau}_{z}=0, u_{z}=0 \text {. }
\end{aligned}
$$

The outer surface of the shell and free from the stress facets of the cut:

$$
\begin{aligned}
& \text { for } r=R+h, \beta \in[0,2 \pi], z \in\left[0, l_{\mathrm{o}} / 2\right] \\
& \qquad \sigma_{z}=0, \vec{\tau}_{r}=0 ; \\
& \text { for } r \in[R, R+h], \beta=0,2 \pi, z \in\left[0, l_{\mathrm{o}} / 2\right] \\
& \qquad \sigma_{\beta}=0, \vec{\tau}_{\beta}=0 .
\end{aligned}
$$

At ends of the shell:

$$
\begin{aligned}
& \text { for } r \in[R, R+h], \beta \in[0,2 \pi], z=l_{\mathrm{o}} / 2 \\
& \text { for } r \in[R, R+h], \beta \in[0,2 \pi], z=0 \\
& \sigma_{z}=0, \vec{\tau}_{z}=0 ; \\
& u_{z}=0, \vec{\tau}_{z}=0 .
\end{aligned}
$$

Here $\sigma_{r}, \sigma_{\beta}, \sigma_{z}, \vec{\tau}_{r}, \vec{\tau}_{\beta}, \vec{\tau}_{z}$ are components of normal and vectors tangential stresses on the contact surfaces respectively, $u_{r}, u_{z}$ are components of displacement; $[\vec{v}]$ is velocity of relative slippage, $\left[u_{r}\right]$ is jump displacements on the contact surface $r=R ; f$ is coefficient of friction; $l, R$ are length and radius of the filler; $l_{\mathrm{o}}, h$ are length and thickness of the shell.

For this research, it is used the hexagonal eight-nodal elements with linear functions for shape [26, 27]. Contact bodies have submitted as separate arrays of finite elements with predetermined number of nodes in the area of contact. Figure 4 presents the scheme of finite-element fragmentation of the shell and the filler for half of the structure. To obtain solutions, it was used a process step by step loading with refining, by iterative method, of boundary conditions for each step. Increases of the load were chosen small to 


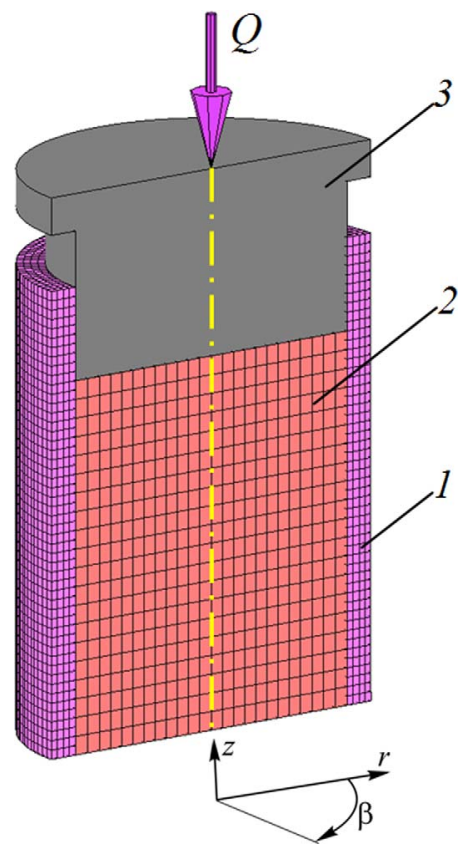

Fig. 4. Scheme of finite-element model for contact interaction the slotted shell with the resilient body: (1) the cylindrical shell with a cut along the generatrix; (2) the low compressible filler; (3) the absolutely rigid piston.

keep a linear relationship between movements and deformations within each loading step.

\section{Analysis of the results}

\subsection{Evaluation of the stress-strain state of the loaded shell}

Some typical results are illustrated graphically. As an example, it is considered the system with the following parameters: shell material: steel, alloyed (yield strength: $\sigma_{T}=950 \mathrm{MPa}$, Young's modulus: $2.1 \times 10^{11} \mathrm{~Pa}$, shear modulus: $8 \times 10^{10} \mathrm{~Pa}$, Poisson's ratio: 0.31 ); filler - high oil and petrol resistance crude rubber (Young's modulus: $2 \times 10^{17} \mathrm{~Pa}$, shear modulus: $7 \times 10^{6} \mathrm{~Pa}$, Poisson's ratio: $0.4995)$; the inner radius of the shell $R=0.08 \mathrm{~m}$; length of shell $0.5 \mathrm{~m}$; length of filler: $0.4 \mathrm{~m}$; thickness of the shell $h=0.015 \mathrm{~m}$; coefficient of friction for pair shell-filler $f=0.5$, a load range on the piston $Q=0-100 \mathrm{kN}$.

Figure 5 shows the distribution of radial displacement $u_{r}$ for the shell with the cut along the generatrix for the characteristic values of azimuth $\beta$. The smallest radial displacements are appearing near the cut, and the largest are at the azimuth $\beta=90$. As a result of contact interaction the filler and the shell, radial movements of the shell along the generatrix are distributed unevenly. Additional analysis showed, if the friction coefficient of pair filler-shell increases this irregularity increases too. At fixed azimuth maximum values of radial movements for the working link are appearing in places near to planes of ends of the pistons. Radial
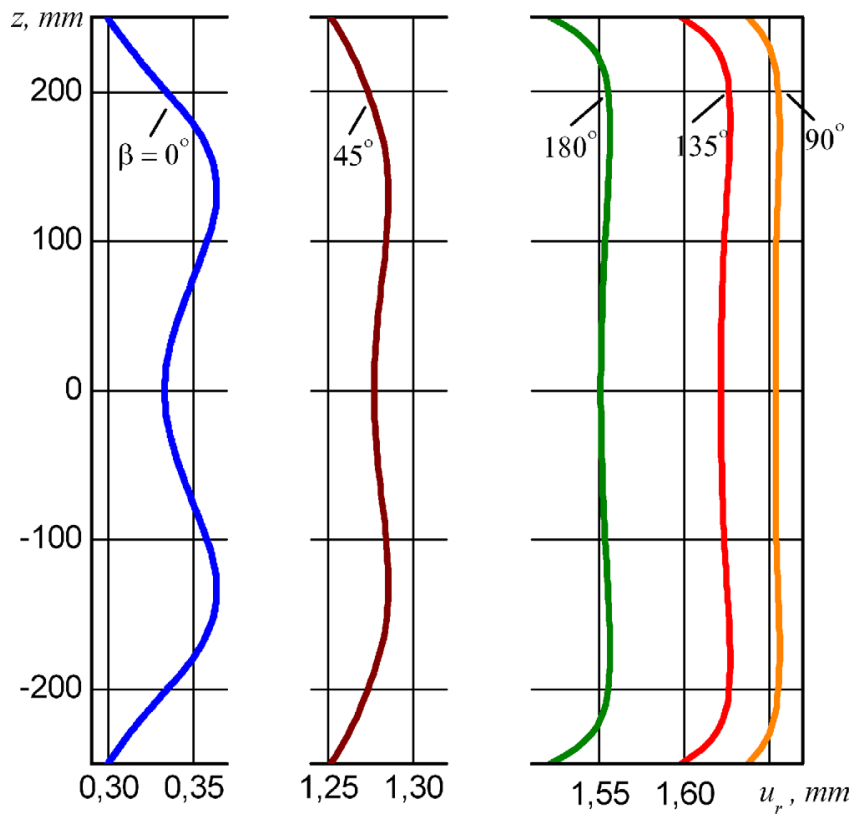

Fig. 5. Distribution of radial movements for the loaded shell with the cut under load on the piston $(Q=100 \mathrm{kN})$.

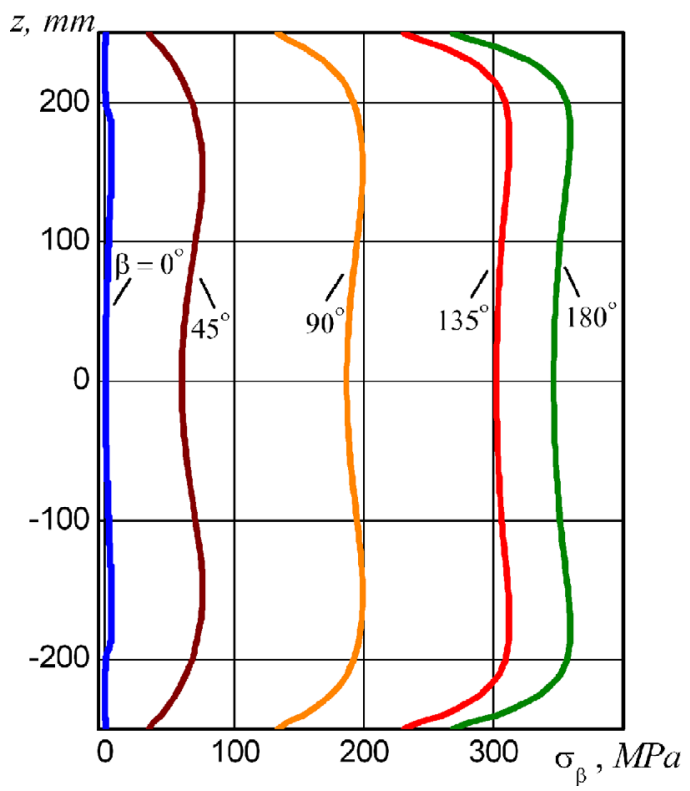

Fig. 6. The distribution ring stresses on the inner surface of the loaded shell with the cut $(Q=100 \mathrm{kN})$.

displacements are reducing if distance from ends of the pistons is increasing. This indicates that increasing the length of the shell and the filler are not accompanied by steady increasing compliance of the structure (authors have seen that, changing the length of the model). It should be noted that the axial movements of the shell compared with radial are small and do not significantly affect on operating characteristics of the resilient element. Therefore, behavior of their values are not shown here. 


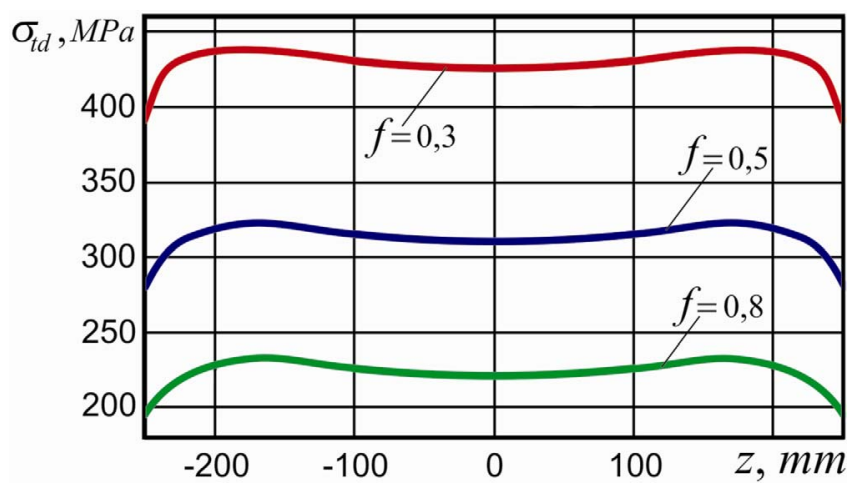

Fig. 7. Evaluation of the strength shell resilient element with the cut at the external load on the piston $100 \mathrm{kN}$.

Figure 6 presents distribution ring stresses $\sigma_{\beta}$ on the inner surface of the shell with the cut along the generatrix for different values of azimuth $\beta$. Analysis of the stress state of shell material indicates that these stresses are crucial at evaluation the strength of the loaded link. Deformation of the slotted shell under contact interaction with the filler leads to change in the values of ring stresses by thickness of the shell. In particular the largest ring tensile stress appears on the inner surface (on the outside - compression), the longitudinal section is the most dangerous at $\beta=180^{\circ}$. Kind change of ring stress values along the generatrix are qualitatively similar to kind change in radial displacements. Obviously the most loaded are cross sections that located near ends of pistons.

During operation the slotted shell resilient element, the most of the shell material is in a difficult state of stress. To evaluate the strength it is used the classic energy criterion Huber-Mises.

In Figure 7 is submitted the distribution of the equivalent stresses $\sigma_{t d}$ in the most dangerous longitudinal section of the shell (the inner surface of the shell, azimuth $\left.\beta=180^{\circ}\right)$. The coefficient of friction between the filler and the shell is varied $f=0.3,0.5,0.8$. Analysis of these dependencies indicates that the limit state of the shell with the cut is achieved first on the inner surface in the ends of the pistons. The ratio of the shell material yield strength $\sigma_{y}$ to the maximum value of equivalent stress indicates on
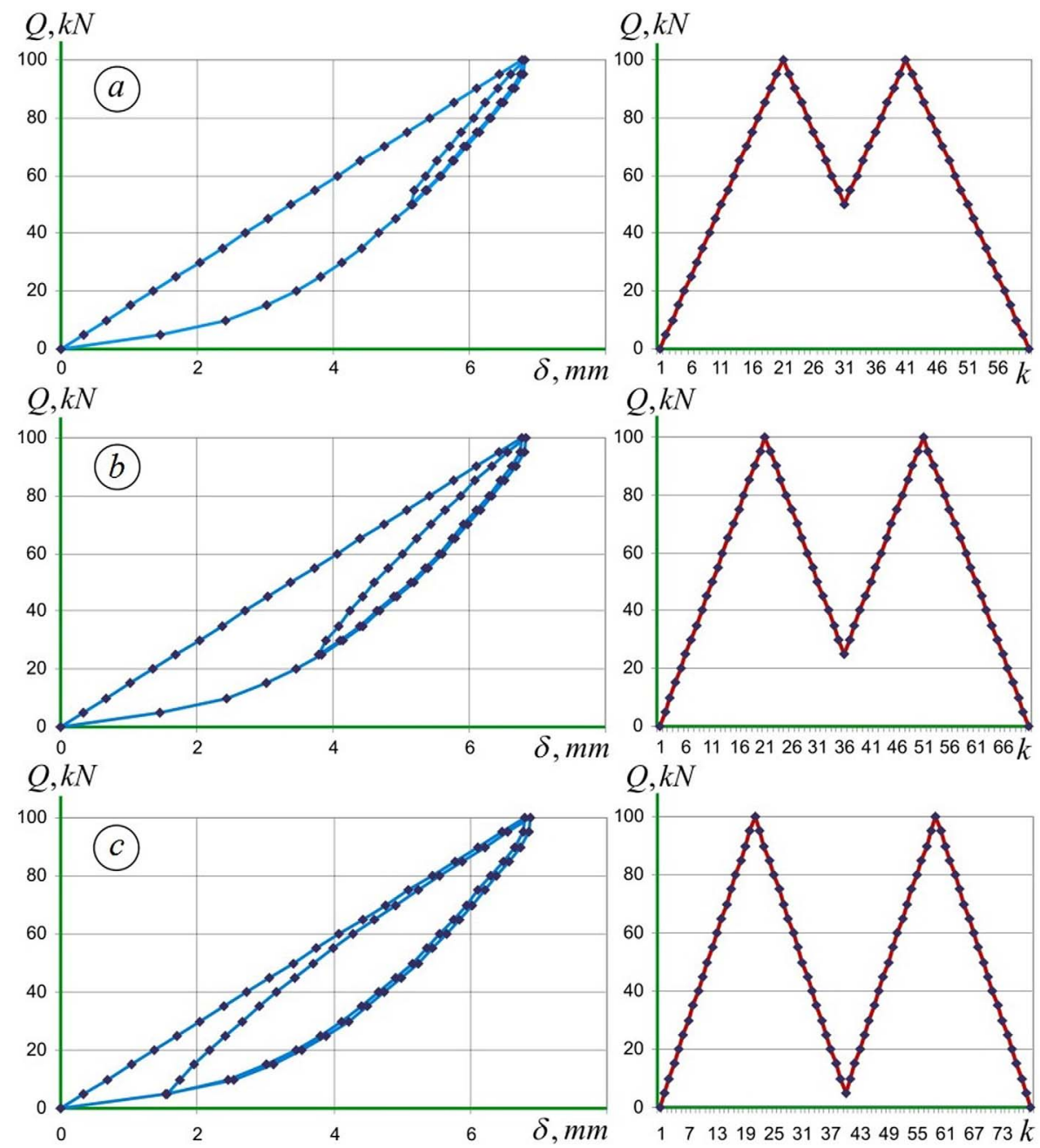

Fig. 8. Diagrams of deformation for the resilient element at different coefficients of asymmetry of cycle loading: (a) $s=0.5$; (b) $s=0.25$; (c) $s=0.05$. 

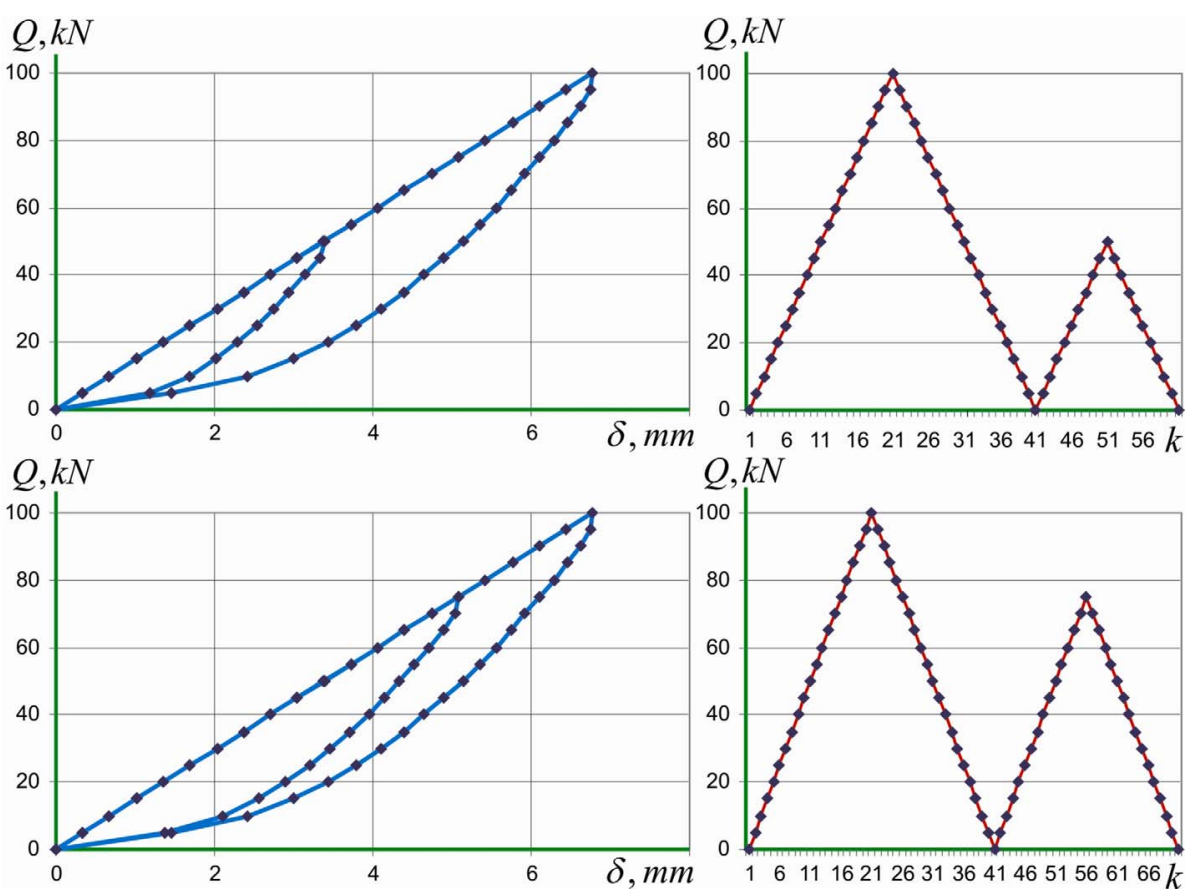

Fig. 9. Diagrams of deformation for the resilient element (from zero cycle load).

the safety margin coefficient of the resilient element. If the coefficient of friction between the filler and the shell is reducing then the safety margin of the construction is decreasing. In particular, for the coefficient of friction $f=0.8$ the safety margin coefficient of the construction is 4.1 , and for $f=0.3$ it is reduced to value of 2.2 .

\subsection{Damping loops of the slotted shell resilient element}

At the initial stage of analysis stress-strain state and the construction of dependencies, shown in Figures 5-7, we assumed that external loads are constant, or monotonically increase. The next stage of the research was devoted to the analysis of hysteresis that occurs in the system slotted shell - resilient body in response to the impact of nonmonotonic loading.

For a few histories changing external load deformation diagrams were constructed for the resilient element (Figs. 8 and 9).

If known diagrams of damping and history of loads we can predict the behavior of the resilient element in an arbitrary time moment and evaluate the value of absorbed energy. In Figures 8 and 9 are submitted loops of damping, they are left, history of loads are right (where $k$ - number of intervals load).

\subsection{Effect tribological parameters on operating characteristics for the resilient element}

Figure 10 illustrates the effect of changing the friction coefficient of the contact pair filler - slotted shell on the view of deformation diagrams for the resilient element. In the graphs, the effect of increasing the compliance of the shell

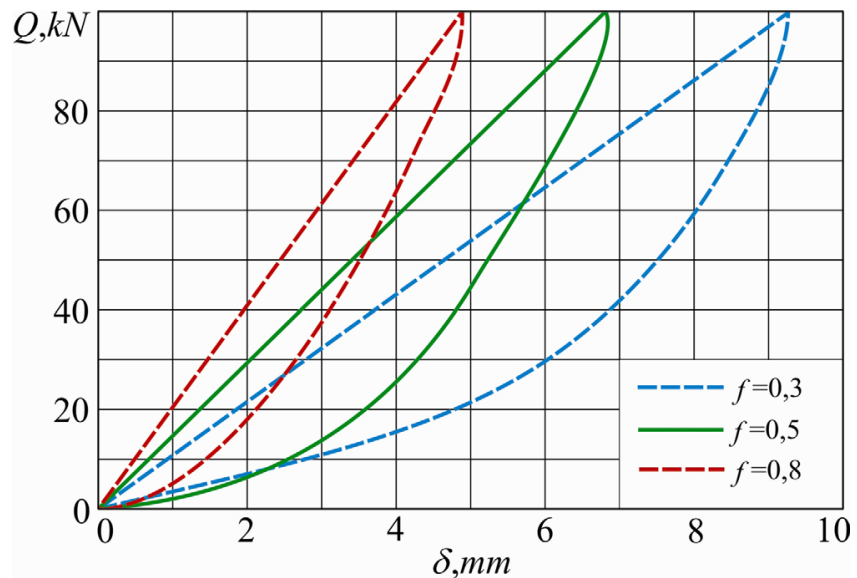

Fig. 10. Diagrams of deformation for the resilient element with different friction coefficients of the contact pair.

spring while reducing the friction coefficient between the filler and the shell is pronounced. The loss of supplied energy to the resilient element by the cycle of load numerically equal to the square of loop damping. For a fixed amplitude of the cycle if the friction coefficient of the pair filler - shell is increased then the value of diffused energy per cycle is gradually reduced (for example, damping loop area for $f=0.8$ by visual less than for $f=0.3$ ). This effect is explained that divided friction systems the distribution of friction forces depends from the deformation of contacting elements, in this case, there are the filler and the shell, but the deformation in its turn depends from the friction forces. This relationship determines the specific, often intuitively unexpected behavior of considered system. 
It is analyzing graphic dependences together, what are shown in Figures $5-10$, and by varying in the design stage geometrical and tribological parameters of the shell resilient element for each model, it is possible to provide balance sufficient strength and required level of damping.

\section{Conclusion}

In the article, the original design of the slotted shell resilient element for the drilling shock absorber is proposed. Using of the cylindrical shell with the cut as the main working part of the device is allowed to combine high load capacity of the construction with relatively low stiffness and required level damping that is sufficient for efficient vibration damping.

To research stress-strain state and to receive operating characteristics of the shell resilient element with the cut, the verified finite-element model of contact interaction of the slotted shell and deformable filler was used. For numerical results, the iterative algorithms were used for solving contact problems based on dry friction on the surfaces of contact.

It is analyzed the stress-strain state of the shell resilient element drilling shock absorber and evaluated the strength of the system. Hysteresis loop is constructed and analyzed for series histories of cyclic loading of the resilient element.

Using the proposed calculation methodology enables efficient to use drilling shock absorbers, to improve the design of shell vibroinsulator for criteria maximum compliance and the required level of damping, creates the preconditions development of new technical solutions to vibration protection systems.

\section{References}

1 Gulyayev V.I., Hudoliy S.M., Glushakova O.V. (2011) Simulation of torsion relaxation auto-oscillations of drill string bit with viscous and Coulombic friction moment models, J. Multi-Body Dyn. 225, 139-152.

2 Kapitaniak M., Hamaneh Vaziri V., Páez Chávez J., Wiercigroch M. (2015) Unveiling Complexity of drill-string vibrations: experiments and modelling, Int. J. Mech. Sci. 101-102, 324-337.

3 Vlasiy O., Mazurenko V., Ropyak L., Rogal O. (2017) Improving the aluminum drill pipes stability by optimizing the shape of protector thickening, EEJET 85, 25-31.

4 Christoforou A.P., Yigit A.S. (2003) Fully coupled vibrations of actively controlled drill-strings, J. Sound Vib. 267, 10291045 .

5 Karkoub M., Abdel-Magid Y., Balachandran B. (2009) Drillstring torsional vibration suppression using GA optimized controllers, J. Can. Petrol. Technol. 12, 32-38.

6 Liao C., Balachandran B., Karkoub M., Abdel-Magid Y.L. (2011) Drill-string dynamics: Reduced-order models and experimental studies, J. Vib. Acoust. 133, 4, 00-00.

7 Velichkovich A.S. (2005) Drilling shock absorber based on a new jacketed spring, Chem. Petrol. Eng. (New York: Springer) 41, 363-366.
8 Hermoso J., Martínez-Boza F.J., Gallegos C. (2017) Modeling pressure-viscosity behavior of oil-based drilling fluids, Oil Gas Sci. Technol. - Rev. IFP Energies nouvelles 72, 18.

9 Pryhorovska T.O. (2017) Study on rock reaction force depending on PDC cutter placement, Mach. Sci. Technol. 21, 36-66.

10 Velichkovich A.S. (2005) Shock absorber for oil-well suckerrod pumping unit, Chem. Petrol. Eng. 41, 544-546.

11 Velichkovich A.S. (2007) Design features of shell springs for drilling dampers, Chem. Petrol. Eng. (New York: Springer) 43, 458-461.

12 Moisyshyn V., Levchuk K. (2017) Investigation on releasing of a stuck drill string by means of a mechanical jar, Oil Gas Sci. Technol. - Rev. IFP Energies nouvelles 72, 27.

13 Toro Downhole Tools (2012) Drilling Tools Catalog, Tomball, Texas USA.

14 Secoroc Rock Drilling Tools (2009) Product catalogue, Rotary products, Atlas Copco Secoroc.

15 VNIIBT (2012) Drilling Tools, Product catalogue, Perm, Russia.

16 Schlumberger (2011) Shock sub impact and vibration reduction sub.

17 Shatskyi I., Popadyuk I., Velychkovych A. (2017) Modelling of energy dissipation in shell dampers, 23rd International Conference Engineering mechanics (Czech Republic, Svratka 15-18 May 2017), Brno University of Technology Institute of Solid Mechanics, Mechatronics and Biomechanics, Svratka, pp. $870-873$.

18 Patent of Ukraine for invention No. 108295, MPK F16F1/40. Resilient element/Velichkovich A. Published. 10.04.2015, Bulletin No. 7. (in Ukrainian)

19 Shopa V.M., Shatskyi I.P., Bedzir O.O., Velychkovych A.S. (2015) Contact interaction of slotted shells with deformable bodies (in Ukrainian), IFNTUOG, Ivano-Frankivsk.

20 Popadyuk I.Yo, Shats'kyi I.P., Shopa V.M., Velychkovych A.S. (2016) Frictional interaction of a cylindrical shell with deformable filler under nonmonotonic loading, J. Math. Sci. New York 215, 243-253.

21 Shatskii I.P., Perepichka V.V. (2013) Shock-wave propagation in an elastic rod with a viscoplastic external resistance, $J$. Appl. Mech. Tech. Phys. 54, 1016-1020.

22 Shatskyi I.P., Ropyak L.Ya, Makoviichuk M.V. (2016) Strength optimization of a two-layer coating for the particular local loading conditions, Strength Mater. 48, 726-730.

23 Shats'kyi I.P., Lyskanych O.M., Kornuta V.A. (2016) Combined deformation conditions for fatigue damage indicator and well-drilling tool joint, Strength Mater. 48, 469-472.

24 Velichkovich A.S., Popadyuk I.I., Shopa V.M. (2011) Experimental study of shell flexible component for drilling vibration damping devices, Chem. Petrol. Eng. (New York: Springer) 46, 518-524.

25 Velichkovich A., Dalyak T. (2012) Experimental verification a finite element model of contact interaction a cut shell with a resilient body (in Ukrainian), Scientific Herald of IFNTUOG 31, 80-86.

26 Zienkiewicz O.C., Taylor R. (2000) The finite element method: Solid mechanics, Vol. 2, Butterworth-Heinemann, Bristol.

27 Larson M.G., Bengzon F. (2013) The Finite element method: Theory, implementation and applications, Springer-Verlag, Berlin Heidelberg. 